\title{
Response of endlessly long shipping channel due to earthquake
}

\author{
Kamila Kotrasová1,* and Eva Kormaníková ${ }^{1}$ \\ ${ }^{1}$ Department of Structural Mechanics, Institute of Structural Engineering, The Technical University of \\ Košice, Faculty of Civil Engineering, Vysokoškolská 4, 04200 Košice, Slovakia
}

\begin{abstract}
Ground-supported tanks are used to store a variety of liquid. The fluid develops hydrodynamic pressure on walls and bottom of tank during an earthquake. This paper provides theoretical background for specification of impulsive and convective actions of fluid in rectangular endlessly long shopping channel container by using analytical methods. This article contains description of methods for solution of response of vertical containment with fluid on the soil, which is subject to horizontal seismic loads.
\end{abstract}

\section{Introduction}

Ground-supported tanks are used to store a variety of liquids, e.g. water for drinking and firefighting, petroleum, chemicals, and liquefied natural gas. When subjected to external excitation like earthquake, liquid-containing structures are challenging to design due to sloshing effects. Indeed, fluid-structure interaction is the source of free surface fluctuation and hydrodynamic pressure loads that can cause unexpected instability or even failure of these structures, [2-6, 11, 21-25].

The seismic analysis and design of liquid storage tanks is, due to the high complexity of the problem, in fact, really complicated task. Number of particular problems should be taken into consideration, for example: dynamic interaction between contained fluid and tank, sloshing motion of the contained fluid; and dynamic interaction between tank and sub-soil. Those belong to wide range of so called fluid structure interactions (FSI). Tanksoil interaction could under specific conditions have a significant effect on seismic response of the tank $[8-10,12$,$] .$

The knowledge of forces, pressures acting onto walls and the bottom of containers and dynamic response of liquid storage tanks during an earthquake plays essential role in reliable and durable design of earthquake resistance structure/facility - tanks [13-20].

\section{Hydrodynamic pressures on the wall and bottom of tank}

The complete solution of the Laplace equation for the motion of fluid contained in a rigid containers can be expressed as the sum of two separate contributions, called "rigid impulsive", and "convective", respectively. The "rigid impulsive" component of the

\footnotetext{
*Corresponding author: kamila.kotrasova@tuke.sk
} 
solution satisfies exactly the boundary conditions at the walls and the bottom of the tank (compatibility between the velocities of the fluid and the tank), but gives (incorrectly, due to the presence of the waves in the dynamic response) zero pressure at the original position of the free surface of the fluid in the static situation. The "convective" term does not alter those boundary conditions that are already satisfied, while fulfilling the correct equilibrium condition at the free surface.

Let us to consider a rectangular ground supported container, having the width $2 L$ as shown in Fig. 1. Walls have uniform thickness. Rectangular container is filled with fluid to the height $H$ and the container is excited by a horizontal acceleration $\ddot{u}_{o}$ in the $X$-direction.
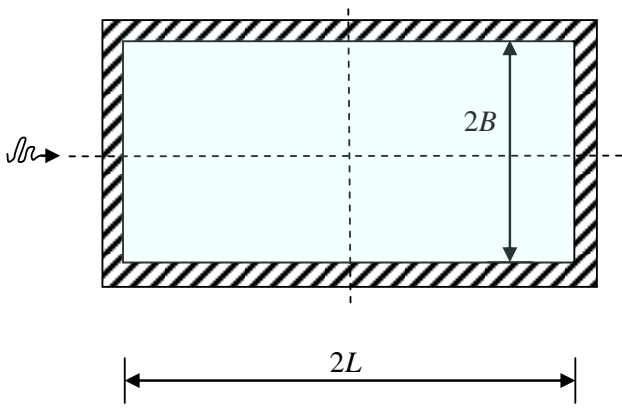
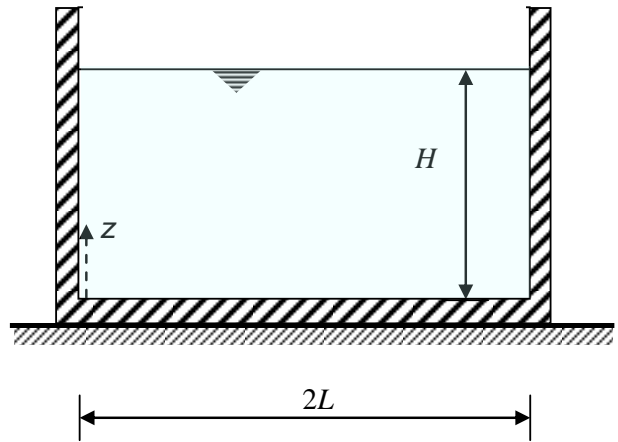

Fig. 1. Geometry of rectangular tanks a) plan, b) sectional elevation.

For rectangular container whose walls can be considered as rigid, a solution of the Laplace equation due to the horizontal excitation, can be obtained in the form (1). The total pressure is given by the sum of an impulsive and a convective contribution using the absolute summation rule [26]

$$
p(z, t)=p_{i}(z, t)+p_{c}(z, t) .
$$

The impulsive component is expressed by

$$
p_{i}(z, t)=q_{0}(z) \rho L A_{g}(t)
$$

where $L$ is the half-width of the tank in the direction of the seismic action, $\rho$ is mass density of the liquid.. The function $q_{0}(z)$ [26] gives the variation of $p_{i}(\cdot)$ along the height. The timedependence of the pressure $p_{i}$ in eq. (2) is given by the function $A_{g}(t) . A_{g}(t)$ is the timehistory dependent ground acceleration in free - field motion of the ground. $p_{i}(\cdot)$ is constant in the direction that is orthogonal to the seismic action.

The convective pressure component is given by the summation of modal terms (sloshing modes), each one having a different variation in time. The dominant contribution for rectangular tanks is the fundamental mode

$$
p_{c 1}(z, t)=q_{c 1}(z) \rho L A_{1}(t)
$$

where the function $p_{c 1}(z)$ is given in [26], together with the contribution $p_{c 2}(z)$ of $2^{\text {nd }}$ mode. $A_{1}(t)$ is the acceleration response function of the simple oscillator having the frequency of the first mode, the appropriate value of the damping, and subjected to an input acceleration $A_{g}(t)$. 


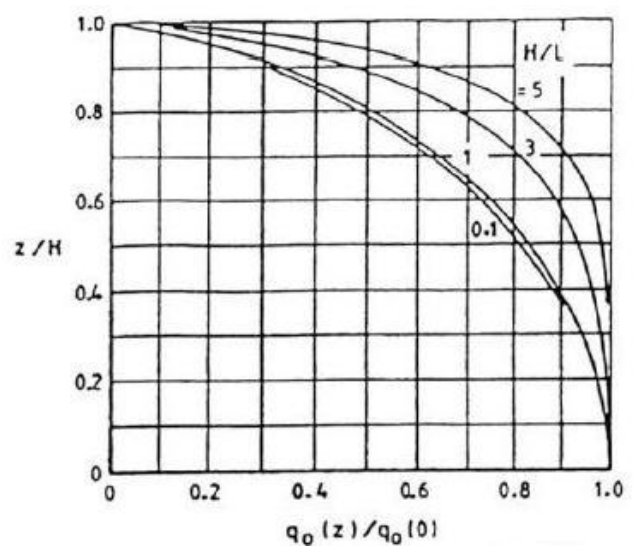

a)

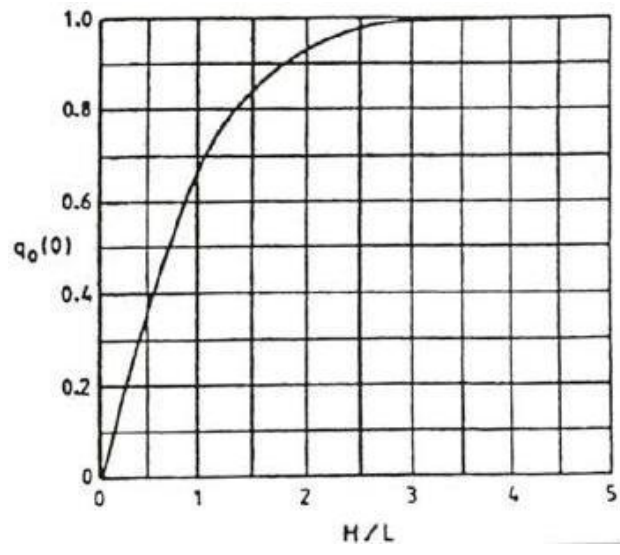

b)

Fig. 2. (a) Dimensionalless impulse pressures at wall of rectangular reservoirs vertical at the direction of seismic excitation; (b) Maximum value of non - dimensional impulse pressures at the direction of seismic excitation [26].
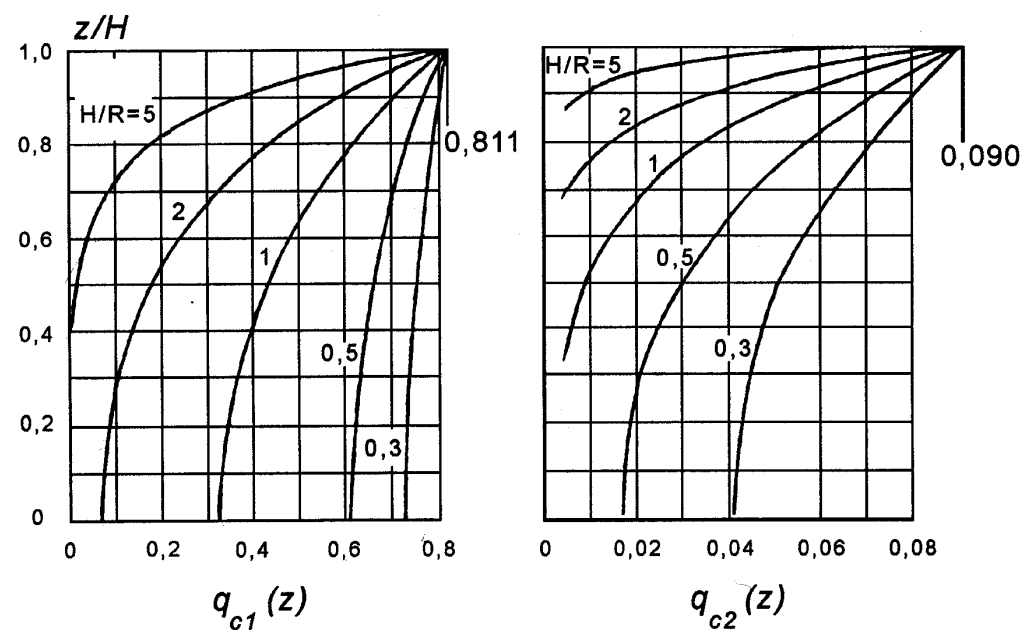

Fig. 3. Dimensionless convective pressures on rectangular tank wall which is perpendicular to the component of the seismic action [26].

The period of oscillation of the first sloshing mode is

$$
T_{c 1}=\sqrt{\frac{L / g}{\frac{\pi}{2} \tanh \left(\frac{\pi}{2} \frac{H}{L}\right)}},
$$

and the impulsive period is

$$
T_{i}=2 \pi \sqrt{\frac{d_{f}}{g}},
$$


where $g$ is gravity acceleration, $d_{f}$ is the deflection of the flexible wall on the vertical centre-line and at the height of the impulsive mass, when the wall is loaded by a load uniform in the direction of the ground motion and of magnitude $m_{i} g / 4 B M$. The width of the tank $2 B$ is perpendicular to the direction of the seismic loading.

A more rough procedure, summarized below, may be adopted. The procedure operates by changing separately the frequency and the damping of the impulsive rigid and the impulsive flexible pressure. In particular, for the rigid impulsive pressure components, whose modified natural period is

$$
T_{i}^{*}=2 \pi \sqrt{\frac{m_{i}+m_{0}}{k_{x} \cdot \alpha_{x}} \cdot \frac{m_{i} \cdot h_{i}^{\prime}}{k_{\theta} \cdot \alpha_{\theta}}},
$$

and modified damping value is

$$
\xi=\xi_{s}+\frac{\xi_{m}}{\left(T^{*} / T\right)^{3}} .
$$

\section{Numerical experiment results and discussion}

As an example case we will assume the ground supported rectangular endlessly long concrete shipping channel, with the length $2 L=5 \mathrm{~m}$ and the height $H_{w}=3 \mathrm{~m}$, where $E=3.4 \cdot 10^{10} \mathrm{~Pa}$, density $\rho=2540 \mathrm{~kg} / \mathrm{m}^{3}$. The endlessly long channel surrounding walls have the uniform thickness of $0.25 \mathrm{~m}$. The channel base slab is $h=0.4 \mathrm{~m}$ thick. Shipping channel is filled with water to the height of $2.6 \mathrm{~m}$, where water density is $\rho_{w}=1000 \mathrm{~kg} / \mathrm{m}^{3}$. There is no roof slab structure covering the shipping channel. This water filled endlessly long concrete shipping channel is grounded on sub-soil $30 \mathrm{MNm}^{-3}$. As the excitation input we consider horizontal earthquake load given by the accelerogram of the earthquake in Loma Prieta, California (18.10.1989). We use the horizontal excitation of this accelerogram in $2 L$ - direction of rectangular channel for the seismic analysis.

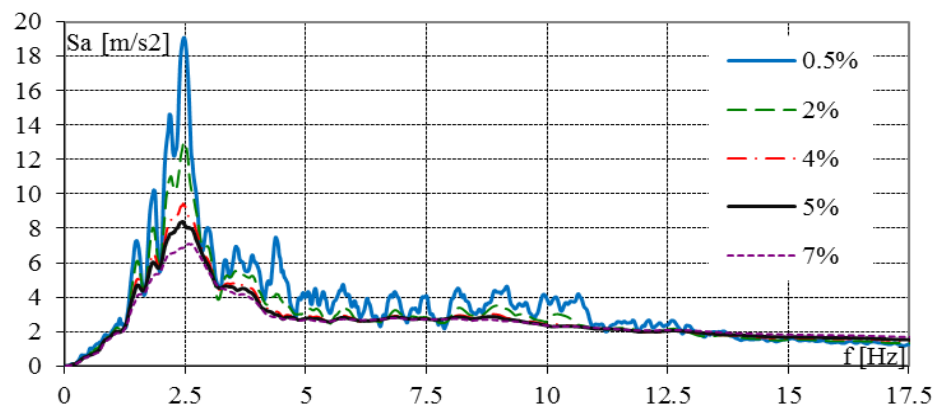

Fig. 4. Elastic response spectrums for accelerogram Loma Prieta

Dynamic response of concrete open top rectangular chipping channel was performed by using Finite Element Method (FEM). The solid walls and the base of the shipping channel was modelled by using 2D SOLID finite element under plain strain condition. The effect of fluid interaction was simulated under the quasi-static conditions. The hydrostatic and hydrodynamic components of the fluid pressures in addition with inertial effects of container were applied as the static load acting onto the walls and the bottom of the tank. The hydrodynamic pressure was given by Eq. (1) - (6). The elastic response spectrums for 
accelerogram Loma Prieta, Fig. 4, was used for the simulation of earthquake. Values of the elastic response spectrums were calculated with regards to the damping ratio $5 \%$ and $0.5 \%$. Value of the elastic response spectrums with the damping ratio 5\% was used for calculation of hydrodynamic impulsive pressure and inertial effect of tank solid. Values of the elastic response spectrums with damping ratio $0.5 \%$ was used for calculation of hydrodynamic convective pressures.

Fig. 5 show:

- the vertical displacement of ground supported rectangular endlessly long concrete full fluid filled shipping channel bottom in [m] - result of seismic analysis (red line),

- the vertical displacement of ground supported rectangular endlessly long concrete fluid empty shipping channel bottom in [m] - result of static analysis (blue dash line).

The bottom of tank is $5.5 \mathrm{~m}$ long. The vertical displacement from static analysis of empty shipping channel bottom is symmetric. The vertical displacement of full fluid filled shipping channel bottom as result of seismic analysis is asymmetric, it is due to considered horizontal earthquake load.

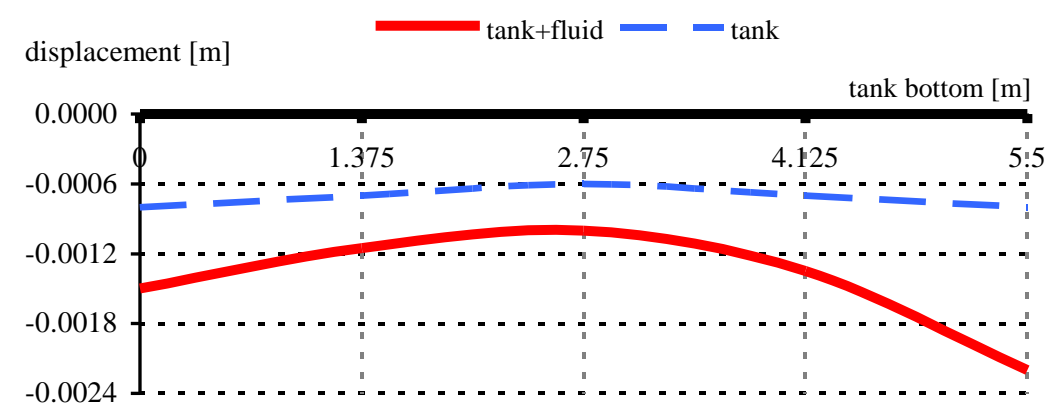

Fig. 5. Vertical displacement of ground supported rectangular endlessly long concrete shipping channel bottom in $[\mathrm{m}]$.

This work was supported by the Scientific Grant Agency of the Ministry of Education of Slovak Republic and the Slovak Academy of Sciences under Project VEGA 1/0477/15.

\section{References}

1. G.K. Batchelor, An introduction to fluid dynamics (Cambridge University Press, Cambridge, 1967)

2. Bathe, K., J., Zhang, H., jr, S., Computer \& Structures, 72, 2 (1999)

3. K.J. Bathe, H. Zhang, M.H. Wang, Computer \& Structures, 56, 2 (1995)

4. K.J. Bathe, H. Zhang, International journal for numerical methods in engineering, (2004)

5. A.Di Carluccio, G. Fabbrocino, E. Salzano, G. Manfredi, ICSV18: 18th The World Conference on Earthquake Engineering, October 12 - 17, Beijing, China (2008)

6. A. H. N. Chegini, G. Pender, WSEAS Transactions on Environment and Development. 8 (2012)

7. G.W. Housner, Earthquake pressures on fluid containers (California institute of technology, Pasadena California, 1955) 
8. G.B. Jacobs, W.S. Don, T. Dittmann, Theoretical and Computational Fluid Dynamics, 26, 1 (2012)

9. N. Jendzelovsky, L. Balaz, Applied Mechanics and Materials, 617, 148-151 (2014)

10. E. Kock, L. Olson, International Journal for Numerical Methods in Engineering, 31, 3 (1991)

11. K. Kralik, J. Kralik jr., Advanced Materials Research, 715, 929-936 (2013).

12. M. Krejsa, P. Janas, V. Krejsa, International Journal of Mathematics and Computers in Simulation, 8, 1 (2014)

13. G. Lajčáková, J. Melcer, Transport and Telecommunication, 16 (2015)

14. P.K. Malhotra, T. Wenk, M, Wieland, Structural Engineering International, 3 (2000)

15. J. Melcer, Journal of Vibrational Engineering and Technologies, vibration engineering \& technologies, 3, 2 (2015)

16. J. Michel, M. Mihalikova, Acta Metallurgica Slovaca, 2, 108-115 (2000)

17. S. Rugonyi, K.J. Bathe, CMES, 2, 2 (2001)

18. H. Sezen, R. Livaoğlu, A. Doğangün, Engineering Structure, 30, 794-803 (2008)

19. M. Safari, WSEAS Transactions on Mathematics, 12 (2013).

20. E. Sávio De Góes Maciel, WSEAS Transactions on Fluid Mechanics, 8, 1 (2013)

21. O. Sucharda, J. Brozovsky, International Journal of Mechanics, 7, 3 (2013)

22. V. Michalcova, S. Kuznetsov, S. Pospisil, International Journal of Mathematics and Computers in Simulation, 8, 1 (2014)

23. X. Wang, Fundamentals of Fluid-Solid Interactions. Analytical and Computational Approaches (Eselvier, Linacre House, Oxford OX2 8DO, 2008)

24. M. Zmindak, I. Grajciar, Computers and Structures, 64, 5-6 (1997)

25. Manual ADINA (71 Elton Ave, Watertown, MA 02472, USA, ADINA R\&D, Inc., wn, October, 2005)

26. STN EN 1998-4. Design of structure for earthquake resistance - Part. 4: Silos, tanks and pipelines (2006) 